\title{
Transnational Ties and Past-Year Major Depressive Episodes among Latino Immigrants
}

\author{
Carmela Alcántara, Ph.D. ${ }^{1}$, Chih-Nan Chen, Ph.D. ${ }^{2}$, and Margarita Alegría, Ph.D. ${ }^{3}$ \\ ${ }^{1}$ Center for Behavioral Cardiovascular Health, Department of Medicine, Columbia University \\ Medical Center, New York, NY \\ ${ }^{2}$ Department of Economics, National Taipei University, Taipei, Taiwan \\ ${ }^{3}$ Center for Multicultural Mental Health Research at Cambridge Health Alliance, Harvard Medical \\ School, Somerville, MA
}

\section{Abstract}

Objective-Latino immigrants live in an increasingly global world where maintaining contact with kin in the home country is easier than ever. We examined: (a) the annual distribution of remittances burden (percentage of remittances/household income) and visits to the home country; (b) the association of these transnational ties with odds of a past-year major depressive episode (MDE); and (c) moderation by Latino sub-ethnicity or gender.

Methods-We conducted weighted logistic regression analyses with the Latino immigrant subsample $(N=1614)$ of the National Latino and Asian American Study.

Results-Mexican and Other Latino immigrants had greater remittances burden than Puerto Rican migrants. Cuban immigrants made fewer visits back home than Puerto Rican migrants. After adjustment for socio-demographics and pre-migration psychiatric history, a percentage increase in remittances burden decreased odds of MDE ( $\mathrm{OR}=0.80$ [95\% CI:0.67-.0.98]), whereas visits back home increased odds of MDE (OR=1.04 [95\%CI:1.01-1.06]). Latino sub-ethnicity was not a significant moderator. Visits back home were more strongly linked to depression among women than men.

Conclusions-The distribution of transnational ties differs by Latino subgroup, although its association with depression is similar across groups. Monetary giving in the form of remittances might promote a greater sense of self-efficacy, social integration, and caregiving for relatives back home that positively affect mental health. Visits back home, especially for women, might signal social stress from strained relationships with kin/spouses/children left behind, or increased caregiving demands that negatively affect mental health. Clinical practice with immigrants should routinely assess the social resources and strains that fall outside national borders.

Correspondence concerning this article should be addressed to Carmela Alcántara Ph.D., at Center for Behavioral Cardiovascular Health, Department of Medicine, Columbia University Medical Center; PH-9, Room 9-319; 622 West $168^{\text {th }}$ Street; New York, NY 10032, ca2543@cumc.columbia.edu; Phone: 212-342-5503; Fax: 212-342-3431.

Conflict of Interest: The authors disclose that they have no conflict of interest. 


\section{Keywords}

Hispanic; immigrants; economic remittances; major depressive episode; psychosocial factors

Latino immigrants compose $53.1 \%$ of the foreign-born population in the United States (United States Census Bureau, 2012). Evidence of transnationalism - the development of frequent and enduring social, economic, political, or cultural ties between two or more countries-among foreign-born Latinos is well documented (Portes, 2003; Schiller, Basch, \& Cristina Szanton, 1995). For example, maintenance of social ties through travel to Mexico, Central America, Dominican Republic, Colombia, Argentina, and Peru to visit friends and family constituted between 19\%-34\% of U.S. resident travel in 2010 (United States Department of Commerce, 2010). Furthermore, economic ties in the form of remittances-money sent by migrants to their countries of origin - to Latin America and the Caribbean totaled $\$ 58.1$ billion in the year 2010, with over $\$ 20$ billion sent to Mexico alone (World Bank, 2011). Yet, despite the available data on the prominence of transnational ties among Latino immigrants, research on the mental health correlates of transnationalism among Latino immigrants is sparse.

\section{Transnational Ties and Mental Health}

Sociological models on the process of immigrant transnationalism emphasize the central role of remittances to the transnationalism process (Portes, 2007). In particular, economic remittances from the migrant in the destination country to the kin and relatives in the country of origin are postulated to initiate and sustain transnationalism. Subsequent trips to the country of origin help create transnational enterprises and maintain social ties, which in turn help form and consolidate transnational communities through the mutual and frequent exchange between migrants, non-migrants, local authorities and governments (Portes, 2007). These dialectical relationships foster the flow of cultural information, ideas, behaviors, identities, and social capital across countries (Levitt, 1998). However, an important component that is missing from these sociological models of immigrant transnationalism is an understanding of the psychology of transnationalism and associations to mental health.

To understand how transnational ties might relate to the mental health of immigrants, we draw from the research literature on social ties and health. Consistent with a social ties model of health, social ties influence mental health through psychosocial pathways that can either buffer or engender stress (Antonucci \& Akiyama, 1987; Antonucci, Fiori, Birditt, \& Jackey, 2010; Cohen, 2004; Cohen \& Lemay, 2007; Umberson, Crosnoe, \& Reczek, 2010). Social ties may positively affect mental health through the provision of instrumental or emotional supports that in turn influence perceptions of individual resources, including how people appraise stress and their perceptions of their own capacity to cope with stress. In contrast, social ties may negatively affect mental health by increasing the frequency and magnitude of negative social interactions that in turn engender psychological stress. In regard to transnational ties, on one hand, transnational ties may broaden opportunities for positive social exchanges that strengthen social resources (e.g., social supports) and individual resources (e.g., perceived capacity to cope) to manage stress, which in turn would lower risk for psychopathology (e.g., depression). On the other hand, transnational ties may 
increase exposure to negative social interactions that contribute to stress and in turn increase risk of psychopathology (e.g., depression).

Importantly, transnational economic ties and transnational social ties appear to be differentially associated with mental health. For example, some research suggests remittances are adversely associated with mental health outcomes such as depression and anxiety, while other research finds a protective association of return visits and correlates of positive mental health (e.g., life satisfaction) (Murphy \& Mahalingam, 2004). Remittances might constitute a source of financial strain for immigrants, who tend to have limited socioeconomic resources (United States Census Bureau, 2011). Thus remittances spending might increase vulnerability to psychopathology in the context of financial burden. Conversely, return visits might facilitate the exchange of positive social interactions and social supports that buffer immigrants from stress and psychopathology.

\section{Gender and Latino Subgroup Considerations in the Psychology of Transnationalism}

Prior research on gender, social ties, and mental health, shows that men and women experience different benefits and drawbacks from their social ties (Antonucci \& Akiyama, 1987; Kessler \& McLeod, 1984; McDonough \& Walters, 2001; Umberson, Chen, House, \& Hopkins, 1996). With regard to gender and transnational ties, while Latino men are more likely than Latino women to travel home to their country of origin, and to send remittances (Itzigsohn \& Giorguli-Saucedo, 2005; Tamaki, 2011), Latina immigrant women are more likely to rely on their social ties in their countries of origin than on their U.S.-based social ties for social support (Viruell-Fuentes \& Schulz, 2009). Together, these findings suggest that remittances might be adversely associated with depression among Latino men because men more often than women assume the financial responsibility for relatives left back home and might experience increased stress in the presence of financial burden due to remittances (Ornelas, Eng, \& Perreira, 2011). In contrast, return visits might be protectively associated with depression, and the protective association might be more salient for women when compared to men because repeat visits back home might increase access to and reliance on social resources that buffer distress. Latino women might be more likely to draw on these social resources to manage stress.

There are also established contextual, socioeconomic, geographic, and political factors that might affect the ease with which specific subgroups of Latino immigrants maintain transnational ties with their country of origin and subsequent association with depression. Indeed, Latino subgroups differ widely in their socioeconomic profiles, context of exit and reception, and migration patterns, and these variations are likely to influence the prevalence of transnational ties and their associations to depression (Alegría et al., 2007; Guarnaccia et al., 2007; Jasso, Massey, Rosenzweig, \& Smith, 2004; Perez, Fortuna, \& Alegría, 2008; Portes, 2003). For example, on average, Puerto Ricans are more likely than Mexicans and Other Latinos to have graduated from high school/college and to live above the poverty line, which might increase the total economic resources Puerto Ricans have to use toward remittances (Guarnaccia et al., 2007). While Mexicans and Other Latinos often have fewer socioeconomic resources, they tend to send large amounts of remittances because non- 
migrants in the country of origin often rely on and expect remittances to sustain their household economies (Duany, 2010; Sana \& Massey, 2005). Thus, Mexicans and Other Latinos might exhibit greater remittances burden when compared to Puerto Ricans, and, the association of this economic burden with depression, might be greater among these groups because of cultural expectations to send remittances.

Moreover, context of exit and federal immigration policies, as well as geographic proximity might also affect the extent to which Latino subgroups visit their home countries and related association with depression. For example, policies that impose travel restrictions to Cuba from the US have historically limited how often Cubans in the US visit Cuba (Rumbaut, 2006). In contrast, Puerto Ricans are able to travel freely to Puerto Rico because of their U.S. citizenship status. Thus, Cubans will be less likely to visit their home countries than Puerto Ricans. Further, some research suggests that those who migrate to escape political violence often engage in more rapid integration practices than those who migrate from countries at peace (Portes, 2003) and thus those who migrate to escape political violence might be less likely to maintain transnational ties and reap the same benefits or distress from these ties. Along these lines, we expected that the association of transnational social ties and depression would be stronger for Puerto Ricans than for Cubans.

Most prior work on transnational movements and health has been narrow in scope and focused on either (a) the influence of economic remittances on physical health among those left behind or the non-migrants in the country of origin (Abas et al., 2009; Andersson, Paredes-Solis, Legorreta-Soberanis, Cockcroft, \& Sherr, 2010; Frank, 2005; Frank et al., 2009; Hamilton, Villarreal, \& Hummer, 2009; Kanaiaupuni \& Donato, 1999; Lindstrom \& Munoz-Franco, 2006; Lu, 2012); or (b) the health of return migrants or those who return to their countries of origin to live following a migratory period (Ceballos, 2011; Davies, Borland, Blake, \& West, 2011; Misra \& Ganda, 2007; Ullmann, Goldman, \& Massey, 2011); neither of these have paid substantive attention to the implications for mental health, and only recently has research started to focus on the implications for health behaviors (Carmela Alcantara, Molina, \& Kawachi, in press). Hence, the extent to which the literature on the health of return migrants or non-migrants can be applied to understand the mental health of immigrants who maintain transnational ties is limited. Other limitations of prior research in this area include a reliance on convenience samples, use of self-report survey measures of mental health symptoms, and failure to examine sub-ethnic and gender group differences.

\section{The Present Study}

Herein, we had two objectives. First, we explored Latino subgroup and gender differences in the distribution of remittances burden (i.e., transnational economic ties) and in the distribution of the number of annual visits to the country of origin (i.e., transnational social ties). We expected Other Latino and Mexican immigrants relative to Puerto Rican migrants to have higher remittances burden because remittances are an essential economic strategy for non-migrants in Mexico and Other Latin American countries (Duany, 2010; Sana \& Massey, 2005). Similarly, we expected Cuban immigrants to make the fewest migration trips relative to the other Latino subgroups because of travel restrictions to Cuba from the U.S. 
during the time the data were collected (Rumbaut, 2006). We expected Latino immigrant men to make more visits to the country of origin and to exhibit greater remittances burden relative to Latino immigrant women.

Second, we examined the association of transnational economic and social ties with pastyear major depressive episode (MDE), and whether Latino subgroup or gender moderated these associations. We selected MDE as our primary outcome because MDE is associated with high role impairment and represents a major public health problem worldwide (Merikangas et al., 2007). Further, there are well-established Latino subgroup and gender differences in the prevalence of MDE (Alegría et al., 2007). We hypothesized that greater remittances burden would be associated with increased odds of MDE because sending economic remittances might represent a source of economic hardship for Latino immigrants, who tend to occupy positions of low socioeconomic status and live in under-resourced communities. Conversely, we hypothesized that number of visits to the country of origin would be associated with a reduction in the odds of MDE because visits back home could in turn broaden the number of total social resources to manage stress. While the research is sparse on how the association of transnational ties with depression might differ by Latino subgroup, we hypothesized that the association of visits back home with depression would be stronger among Puerto Ricans than Cubans. In regard to gender, we hypothesized that the adverse association of remittances with depression would be stronger for men than women, and that the protective association of visits to home country with depression would be stronger for women than for men. To our knowledge, this is one of the first analyses on the association between economic remittances, visits to country of origin, and a psychiatric syndrome (i.e., major depressive episode), among a nationally representative sample of Latino immigrants.

\section{Method}

\section{Data Source and Sample}

Our data are drawn from the National Latino and Asian American Study (NLAAS), which was conducted between 2002 and 2003 (Alegria et al., 2004; Heeringa et al., 2004). The NLAAS used a multi-stage probability sampling design to examine how race/ethnicity, socioeconomic status, and environmental context pattern risk for psychiatric morbidity and health service use among a nationally representative sample of English-speaking and nonEnglish speaking Latino and Asian American adults. The NLAAS sampling strategy included: core sampling of primary and secondary sample units and high-density supplemental sampling of geographic areas composed of more than 5\% of the targeted ethnic groups (Heeringa et al., 2004). The overall weighted response rate for the NLAAS was $73.2 \%$. We restricted our analyses to Latino immigrants who migrated to the US mainland $(N=1614)$ because the remittances and visits questions were asked only of the immigrant subsample. Our sample included Puerto Rican migrants who were born on the island of Puerto Rico $(n=212)$, and foreign-born Cubans $(n=500)$, Mexicans $(n=480)$, and Other Latinos $(n=422)$. 
Transnational ties-We operationalized transnational economic ties as remittances burden, which refers to the percentage of the total remittances sent in past-year relative to household income. We calculated this percentage using participants' responses to a question about their household income, and the question item: "How much money do you send home per month or per year?"; monthly responses were recalculated as yearly amounts.

Transnational social ties was operationalized as the number of annual visits to the country of origin, which was measured with a single item asking respondents "How many times have you returned to your country of origin in the last year?" This variable was used as a continuous measure (range $=0-36$ ).

Major depressive episode-Past-year MDE was diagnosed using the World Mental Health-Composite International Diagnostic Interview (WMH-CIDI; Kessler \& Üstün, 2004), which was administered by trained interviewers. The WMH-CIDI is a lay-administered and fully-structured diagnostic interview based on the criteria of the Diagnostic and Statistical Manual of Mental Disorders IV (DSM-IV) (American Psychiatric Association, 2000) with proven validity and reliability for the assessment of mental disorders that has been commonly used in psychiatric epidemiology studies in the US and across the world. The WMH-CIDI has been translated and tested for use in several languages including Spanish. Clinical calibration studies have shown that the WMH-CIDI has good-to-excellent concordance with the gold standard in psychiatric assessment (Structured Clinical Interview for DSM-IV; SCID) for diagnosing any major depressive disorder in non-Latinos (Area Under the Curve $[\mathrm{AUC}]=0.83$; kappa $[\mathrm{K}=0.56]$ ) and Latinos (AUC $=0.67 ; \mathrm{K}=0.38$ ) (Alegria et al., 2009; Haro et al., 2006). To meet criteria for MDE, respondents had to endorse at least five of nine symptoms of depression as defined in the DSM-IV during the same two week period in the past-year, with at least one symptom including depressed mood or loss of interest/pleasure (American Psychiatric Association, 2000). The mental disorders are assessed using DSM-IV criteria and organic exclusions and diagnostic hierarchy rules were applied in making diagnoses. Sample items include: During that period of (several days/two weeks) or longer, did you feel discouraged about how things were going in your life most of the day nearly every day? ; Did you have a much smaller appetite than usual nearly every day during that period of (several days/two weeks)?

Gender-Participants' gender was measured using a dichotomous variable indicating whether participants' self-identified as male (reference) or female.

Latino sub-ethnicity-Sub-ethnicity was assessed as self-reported race/ancestry in Cuba, Mexico, Puerto Rico, or Other Latin American country (e.g., Colombia, Nicaragua, Ecuador, Dominican Republic). Puerto Rico served as the reference category.

Covariates-Respondents' age category at interview (18-34 [reference], 35-49, 50-64, 65 or more), duration in U.S. (under 5 years [reference], over 5 years), English proficiency (fair/poor [reference], good/excellent), age at migration to the U.S. (0-6 [reference], 7-17, 18 and above), household income (0-\$14,999 [reference], $\$ 15,000-\$ 34,999, \$ 35,000$ 74,999 , greater than or equal to $\$ 75,000$ ) and educational attainment level (less than or equal 
to11 years [reference], 12 years, 13-15 years, more than or equal to 16 years) were included in our model as covariates. We also created a dichotomous variable to indicate presence or absence of pre-migration psychiatric history and included this variable in our models as a covariate. Responses were coded as " 1 " for pre-migration psychiatric history if participants met $D S M-I V$ lifetime criteria for any of the psychiatric conditions assessed in the WMHCIDI and they reported an age of onset that corresponded to a time period before they migrated to the U.S. mainland as ascertained in the NLAAS questionnaire. The psychiatric conditions assessed in the WMH-CIDI included: major depressive episode, dysthymia, agoraphobia, panic disorder, social phobia, alcohol dependence, alcohol abuse, drug dependence, drug abuse, generalized anxiety disorder, posttraumatic stress disorder, bulimia, and anorexia.

\section{Analytic Strategy}

All inferential procedures accounted for the complex survey design and were conducted using STATA statistical software version 10.1 (Stata Corporation, 2008). Survey weights were used for all estimation procedures. Less than one percent of participants $(n=16)$ were missing data for any one of the outcome or explanatory variables, which is less than the 5\% recommended for imputation (Tabachnick \& Fidell, 2007). There was no evidence of multicollinearity.

Distribution of Transnational Economic and Social Ties and MDE-We used an Omnibus test to examine whether the distribution of past-year MDE and transnational ties, and covariates differed by Latino sub-ethnic group. When the Omnibus test was significant, we conducted pair-wise comparisons using adjusted Wald tests to determine whether Mexican, Other Latino, or Cuban immigrants, were statistically different from Puerto Ricans who we selected as the reference group. Puerto Rican migrants were selected as the reference group in all analyses because this sub-ethnic group exhibits the highest rates of MDE relative to the other Latino sub-ethnic groups (Alegría et al., 2007). We also used a Wald test to examine whether the distribution of transnational ties differed by gender.

\section{Association of Transnational Economic and Social Ties with MDE-We}

conducted a series of weighted logistic regression analyses with our full sample to test three models. First, we estimated the bivariate association between each transnational tie and pastyear MDE. Next, we modeled the odds of meeting criteria for a major depressive episode by building three sequential models. Models 1 to 2 included each type of transnational tie separately (i.e., remittances burden, number of visits back home) along with the main effect of gender and sub-ethnicity. Model 3 included each transnational tie, gender, and subethnicity, simultaneously. Final models included two-way interactions between each transnational tie and gender (Model 4; female gender X remittances proportion, female gender $\mathrm{X}$ annual visits interaction term), and two-way interactions between each transnational tie and sub-ethnicity (Model 5; sub-ethnicity X remittances interaction, subethnicity $\mathrm{X}$ annual visits interaction). All models adjusted for socio-demographic covariates (age, gender, English proficiency, years in U.S., educational attainment, household income, and age at migration) and pre-migration psychiatric history. We tested for differences in slopes through regression coefficients associated with the product term, and we calculated a 
joint F-test, which is a general Omnibus tests to determine whether the interaction terms were significant. If significant, we used coefficients from Models 4 or 5 to calculate predicted probabilities of MDE and plotted them to illustrate significant moderating effects. We used the "recycled predictions" method (Stata Corporation, 2008) to generate model coefficients for each interaction term that assumes that each subgroup has the average characteristics of the entire Latino immigrant population (for examples see Davern, Rodin, Blewett, \& Call, 2007; Graubard \& Korn, 1999).

\section{Results}

\section{Participants}

Table 1 presents the weighted descriptive characteristics of the NLAAS Latino immigrant subsample, and weighted age and gender adjusted prevalence rates for past-year MDE. Latino sub-ethnic groups differed from each other in the distribution of age, Englishproficiency levels, household income, educational attainment, and age at migration. Overall, the age and gender adjusted past-year prevalence of depression was $8.27 \%$. Puerto Rican migrants $(N=144,13.26 \%)$ had the highest weighted age and gender adjusted past-year prevalence rates for MDE relative to Cuban $(N=48,8.64 \%)$ and Mexican $(N=33,6.65 \%)$ immigrants. Pre-migration rates of psychiatric disorder also varied significantly by Latino sub-ethnic group. Mexican immigrants $(N=22,11.22 \%)$ were less likely than Puerto Rican migrants $(N=35,18.20 \%)$ to have met criteria for a psychiatric disorder with a reported an age of onset prior to migration.

\section{Distribution of Transnational Economic and Social Ties}

Our first objective was to examine whether the prevalence and distribution of transnational economic and social ties varied by Latino sub-ethnic group or gender (Table 1). Mexican $(M=17.26 ; S D=0.74)$ and Other Latino $(M=14.27 ; S D=0.78)$ immigrants exhibited greater remittances burden than Puerto Rican migrants $(M=0.74 ; S D=0.04)$ and Cuban immigrants $(M=7.59 ; S D=1.62)$. We note that the median dollar amount of past-year remittances equaled \$1,200 per year for the entire sample (data not shown). Mean number of annual visits to country of origin did not differ substantially between Puerto Rican migrants $(M=0.50 \mathrm{SD}=1.61)$, Mexican $(M=1.32 \mathrm{SD}=3.22)$, and Other Latino $(M=0.38 \mathrm{SD}=0.63)$ immigrants. However, Cubans $(M=0.16 \mathrm{SD}=1.27)$ made the fewest trips to the country of origin in the past-year. With regard to gender and transnational ties, neither remittances burden (men: $M=0.14 \mathrm{SE}=0.04$; women: $M=0.15 \mathrm{SE}=0.03$ ), nor number of annual visits (men: $M=0.78 \mathrm{SE}=0.24$; women: $M=1.00 \mathrm{SE}=0.58$ ) varied by gender (see note in Table 1 ).

\section{Transnational Economic and Social Ties and Major Depressive Episodes}

Our second objective was to examine the association of transnational economic and social ties with past-year MDE and to test for ethnic and gender interactions. Table 2 shows the weighted adjusted models for past-year MDE. At the bivariate level, number of visits to the home country was associated with increased odds of past-year MDE (Odds Ratio $[\mathrm{OR}]=1.03,95 \% \mathrm{CI}[$ Confidence Interval $]=1.00,1.05)$, whereas remittances burden was associated with reduced odds of past-year $\mathrm{MDE}(\mathrm{OR}=0.84 ; 95 \% \mathrm{CI}=0.71,0.98)$. After adjustment for socio-demographics, and pre-migration psychiatric history, an incremental 
increase in remittances burden was statistically associated with a $20 \%$ reduction in the odds of past-year MDE (OR=0.80, 95\% CI=0.67, 0.97) (Model 1). In contrast, an incremental visit in the number of annual visits to the country of origin was associated with a $4 \%$ increase in the odds of past-year MDE ( $\mathrm{OR}=1.04,95 \% \mathrm{CI}=1.01,1.06)$ in adjusted models (Model 2). Both the adverse association of number of visits to the country of origin $(\mathrm{OR}=1.04,95 \% \mathrm{CI}=1.01,1.06)$ and the protective association of remittances burden $(\mathrm{OR}=0.81,95 \% \mathrm{CI}=0.67,0.98)$ with depression persisted when both transnational ties were entered simultaneously in the fully-adjusted model (Model 3).

We did not find a statistically significant remittances burden by sub-ethnicity interaction ( $p=.77)$, number of visits by Latino sub-ethnicity interaction $(p=.83)$, or remittances burden by gender interaction $(p=.17)$. However, the number of visits by gender interaction term was significant $(p=.000)$, such that the adverse association between number of visits to the country of origin and depression was much more pronounced for Latino immigrant women than Latino immigrant men (see Figure, and Table 3).

\section{Discussion}

This article characterizes the distribution of transnational ties among Latino immigrants and provides a snapshot of the association of transnational ties with depression. We review our main findings below.

\section{Distribution of Transnational Ties}

Our first objective was to determine whether there were any differences across the major Latino subgroups or by gender in the prevalence and distribution of transnational ties. As expected, Mexicans and Other Latino immigrants relative to Puerto Rican migrants exhibited greater remittances burden, which converges with the objective data showing that Mexican and Other Latino immigrants (e.g., Dominican immigrants) send more monthly remittances (as measured by U.S. dollars) than Puerto Rican migrants, despite having lower per capita income (Duany, 2010). Remittances are often used to sustain the economic livelihoods of the non-migrants left behind, especially those with few economic assets and resources (Duany, 2010). Unlike Mexico and other Latin American countries, where remittances are an essential survival strategy among the poor, the existence of a viable safety net in Puerto Rico (federal subsidies for food and housing, social security) may offset the use of remittances to cover basic necessities among the poorest sectors of the population in Puerto Rico (Sana \& Massey, 2005). Furthermore, Mexican and Other Latino immigrants relative to Puerto Rican migrants may have more relatives and friends living in their respective countries of origin; such kinship ties may increase their likelihood to send remittances (Duany, 2010). As we expected, Cuban immigrants relative to Puerto Rican migrants made the fewest annual visits to their country of origin, which likely reflects the presence of barriers to return migration (Guarnaccia et al., 2007) due to imposed travel restrictions to Cuba from the US and greater likelihood to have migrated due to political persecution (Rumbaut, 2006).

Contrary to our hypothesis, we did not find evidence that the prevalence of transnational ties varied by gender in this immigrant sample. In other words, Latino immigrant men and 
women exhibit similar remittances burden and visit patterns. This implies that whatever differences emerge in the association between transnational ties and depression are not related to differential or uneven distribution of transnational ties by gender.

\section{Transnational Ties and Depression: The Role of Gender}

Our second objective was to identify whether transnational ties were associated with pastyear MDE among Latino immigrants, and then to determine whether gender or Latino subethnicity of the immigrant moderated these associations. We found that the association of transnational ties with depression did not differ by Latino sub-ethnicity, but, in some instances, differed by gender.

Remittances and Depression-A percentage increase in relative remittances burden (i.e., dollars spent toward economic remittances as a function of household income) resulted in a 16-20\% decrease in the odds of past-year MDE, which countered our initial hypothesis. It is possible that for Latino immigrants, the more income devoted towards remittances for relatives back home, the more likely they are to perceive a congruence between their premigration expectations or reasons for migrating and post-migration lived realities, which in turn might generate positive psychological states that protect against poor mental health. Indeed, prior research shows that high perceived congruence between pre-migratory expectations and post-migratory outcomes is associated with an increase in perceived life satisfaction and a decrease in depressive symptoms among a sample of Caribbean West Indian immigrants (Murphy \& Mahalingam, 2006). Furthermore, a focus on altruistic behaviors (Schwartz, Meisenhelder, Ma, \& Reed, 2003), in this case, monetary giving in the form of economic remittances, might promote a greater sense of self-efficacy, social integration, and caregiving for kin left behind that in turn positively affect mental health, and lower risk for depression.

It is also possible that Latino immigrants who exhibit greater remittances burden might be those who occupy positions of high social status in the country of origin or those who experienced upward social mobility post-migration. Remittances might then be used as a strategy to maintain an immigrant's social position in the home country. Perceptions of high social position in turn might buffer them from psychopathology (C. Alcantara, Chen, \& Alegria, 2014; Franzini \& Fernandez-Esquer, 2006). To this end, research shows that immigrants who accrued sufficient economic resources in the host country (i.e., experienced upward social mobility) or those who arrived with socioeconomic resources were more likely to participate in transnational economic exchanges (Itzigsohn \& Saucedo, 2002; Tamaki, 2011). We note that immigrants who send economic remittances might experience negative mental health effects only in the context of severe financial strain or after crossing an economic threshold. For instance, in our sample, the highest relative remittances burden was $17.26 \%$, meaning that Latino immigrants in this sample spent on average slightly over $17 \%$ of their household income on remittances. However, it is quite possible that immigrants who spend over $50 \%$ of their household income on remittances might be the ones who are more likely to exhibit higher odds of depression due to the presence of severe financial strain. Future research should examine whether there are threshold effects associated with remittances burden and depression. 
Visits Back Home and Depression-In regard to transnational social ties and mental health, each incremental visit back home was associated with a 3-4\% increase in meeting criteria for a past-year MDE. This association was most pronounced among Latino immigrant women. Latino immigrants who make multiple trips back home might be those who perceive high levels of loneliness because of fragmented social relationships or minimal social integration in the country of origin and the U.S. mainland. Research shows that perceived loneliness - feelings of distress when individuals perceive unmet social needs with respect to the quality or quantity of social relationships - is associated with poor mental health outcomes (Hawkley \& Cacioppo, 2010; Pressman et al., 2005). Thus, perceived loneliness may mediate the relationship between number of annual visits back home and past-year MDE.

The adverse association between visits to the country of origin and MDE might also reflect the emotional toll associated with maintaining social ties abroad. Latino immigrants who remain highly socially integrated into their countries of origin while residing in the U.S. mainland may bear additional stressors from the effort exerted to actively maintain social ties in their countries of origin. These immigrants might also have stronger kinship ties in the home country because of children, spouses, or parents left behind, and thus subject to periods of family separation or social train that in turn might negatively impact their mental health. To this end, Latino immigrants may be compelled to travel to their country of origin to take care of ailing relatives or visit spouses, children, or family members left behind due to the emphasis on familismo or the prizing of interconnectedness among kin and extended relatives and the prioritization of family goals over individual goals (Laria \& LewisFernández, 2006; Sabogal, Marín, Otero-Sabogal, \& Marín, 1987). Our results suggest that there are emotional costs associated with traveling back and forth, and these adverse associations are more pronounced for Latino immigrant women than for Latino immigrant men, which might reflect gendered cultural norms regarding caregiving that disproportionately place caregiving demands on women (Hondagneu-Sotelo, 1999). Strained family ties, even in the context of familial support, may be particularly predictive of poor mental health for Latino immigrant women (Molina \& Alcantara, 2013). Future research should examine the interpersonal and emotional costs and benefits of maintaining a high level of transnational social integration among Latino immigrants, especially immigrant women.

Last, but not least, visits back home may reflect aspects of the "salmon bias," which proposes that Latino immigrants in poor physical health return to their country of origin to die, although we highlight that the evidence in support of the salmon bias has been mixed (Abraido-Lanza, Dohrenwend, Ng-Mak, \& Turner, 1999; Jasso et al., 2004). Although the Latino immigrant respondents in the NLAAS sample were living in the U.S. mainland at the time the study was conducted, it is possible that number of annual visits back home serves as a proxy for perceived mental/physical health status or unmet health service needs. Future research should examine more closely the mental health profiles and health service needs of transnational immigrants. 


\section{Limitations}

Although our findings represent significant contributions to the literature on immigrant mental health, there are several limitations that merit discussion. First, the data collected within the NLAAS are cross-sectional and therefore do not allow us to make causal inferences or determine causal order. It is possible that whether or not an immigrant is depressed determines how often he or she visits the country of origin and how much he or she contributes in economic remittances, rather than the inverse. Notwithstanding, a major strength of this article is that we were able to adjust for pre-migration psychiatric history to limit confounding that could be attributable to health selection, or the migration of the relatively healthier segments of the population (Jasso et al., 2004), in this case mental health selection. Future research should use longitudinal models to assess the prospective relationship between transnational ties and depression. Second, we used retrospective selfreport measures of transnational ties, which are subject to recall bias, which might lead to under or over estimates of the associations observed. Last, we do not have data on reasons for visits back home, which may help capture the context of visits and explain associations to past-year MDE. We also do not have any information about the documentation or legal status of the immigrants in our sample. It is possible that the stress associated with undocumented or illegal status might account for decisions to travel back home and association to depression. Future research should examine the context of return migration and associations to mental health. Third, although we did not find evidence that Latino subethnicity moderated these associations, it is plausible that other contextual factors such as age at migration to the US might moderate these associations. We conducted supplemental analyses to address this question but we did not find evidence of moderation by age at migration in this sample. However the majority of the NLAAS sample arrived in the U.S. as adults thus we were underpowered to find statistically significant interactions for those who migrated as children or adolescents. Future research should examine whether age at migration and other contextual factors such as when immigrants arrived in the US and context of reception might affect prevalence of transnational ties and associations to depression.

\section{Conclusion}

Nearly 40 million people in the United States are foreign-born and actively maintain ties to their countries of origin while adapting to the U.S. mainland (United States Census Bureau, 2012). Our results suggest that transnational contact is prevalent among Latino immigrants and that some transnational ties may be beneficial and others harmful to the mental health of Latino immigrants. For example, remittances burden was associated with decreased odds of depression, whereas visits back home were associated with increased odds of depression. Further, women were more likely than men to exhibit increased prevalence of depression with each incremental visit back home. Our results imply that culturally competent approaches to clinical care should include the careful assessment of an immigrant's social world, and as such inquire into the characteristics and nature of local and global social ties that may either buffer or generate social distress and psychopathology for Latino immigrants. For instance, clinicians working with Latino immigrant clients who often travel back and forth between the US and the home country should assess the context for the return 
visit. Special attention should be given to immigrant women and the potentially distressing context under which visits back home are initiated. In anticipation of travel back home, Latino immigrants, especially women, might benefit from learning adaptive coping strategies (that are consonant with the cultural values of familism) to manage the social demands associated with return visits. In sum, research on the psychology of transnationalism, or the psychological factors that shape the type and level of transnational contact, and how transnational ties relate to the mental health of immigrants represents a necessary and timely research area if we are to design interventions to better serve immigrant clients living in an increasingly global world.

\section{Acknowledgments}

C. Alcántara was supported by K24 HL-84034 and HL115941-01S1 from the National Heart, Lung, and Blood Institute of the National Institutes of Health. M.Alegría and C.Chen were provided research support from the National Center on Minority Health and Health Disparities (UPR-CHA Research Center of Excellence: Making a Difference for Latino Health: \# 5 P60 MD 002261). The content of this manuscript is solely the responsibility of the authors and does not necessarily represent the official views of the National Institutes of Health.

\section{References}

Abas MA, Punpuing S, Jirapramukpitak T, Guest P, Tangchonlatip K, Leese M, Prince M. Rural-urban migration and depression in ageing family members left behind. Br J Psychiatry. 2009; 195(1):5460.10.1192/bjp.bp.108.056143 [PubMed: 19567897]

Abraido-Lanza AF, Dohrenwend BP, Ng-Mak DS, Turner JB. The Latino mortality paradox: a test of the "salmon bias" and healthy migrant hypotheses. Am J Public Health. 1999; 89(10):1543-1548. [PubMed: 10511837]

Alcántara C, Chen CN, Alegria M. Do post-migration perceptions of social mobility matter for Latino immigrant health? Soc Sci Med. 2014; 101:94-106.10.1016/j.socscimed.2013.11.024 [PubMed: 24560229]

Alcántara, Carmela; Molina, Kristine M.; Kawachi, Ichiro. Transnational, Social, and Neighborhood Ties and Smoking Among Latino Immigrants: Does Gender Matter? American Journal of Public Health. (in press).

Alegría, Margarita; Mulvaney-Day, Norah; Torres, Maria; Polo, Antonio; Cao, Zhun; Canino, Glorisa. Prevalence of psychiatric disorders across Latino subgroups in the United States. American Journal of Public Health. 2007; 97(1):68-75. [PubMed: 17138910]

Alegría, Margarita; Shrout, Patrick E.; Torres, Maria; Lewis-Fernández, Roberto; Abelson, Jamie M.; Powell, Meris; Canino, Glorisa. Lessons learned from the clinical reappraisal study of the Composite International Diagnostic Interview with Latinos. Int J Methods Psychiatr Res. 2009; 18(2):84-95. [PubMed: 19507168]

Alegría, Margarita; Takeuchi, David; Canino, Glorisa; Duan, Naihua; Shrout, Patrick; Meng, Xiao-Li; Gong, Fong. Considering context, place and culture: The National Latino and Asian American Study. Int J Methods Psychiatr Res. 2004; 13(4):208-220. [PubMed: 15719529]

American Psychiatric Association. Diagnostic and statistical manual of mental disorders : DSM-IVTR. Washington, DC: American Psychiatric Association; 2000. (4th, text revision 2000 ed.)

Andersson N, Paredes-Solis S, Legorreta-Soberanis J, Cockcroft A, Sherr L. Breast-feeding in a complex emergency: four linked cross-sectional studies during the Bosnian conflict. Public Health Nutr. 2010; 13(12):2097-2104.10.1017/s1368980010001667 [PubMed: 20576196]

Antonucci, Toni C.; Akiyama, Hiroko. An examination of sex differences in social support among older men and women. Sex Roles. 1987; 17(11-12):737-749.10.1007/bf00287685

Antonucci, Toni C.; Fiori, Katherine L.; Birditt, Kira; Jackey, Lisa MH. Convoys of social relations: Integrating life-span and life-course perspectives. In: Lamb, ME.; Freund, AM.; Lerner, RM., editors. The handbook of life-span development, Vol 2: Social and emotional development. Hoboken, NJ US: John Wiley \& Sons Inc; 2010. p. 434-473. 
Ceballos M. Simulating the effects of acculturation and return migration on the maternal and infant health of mexican immigrants in the United States: a research note. Demography. 2011; 48(2): 425-436.10.1007/s13524-011-0017-4 [PubMed: 21533661]

Cohen S. Social relationships and health. Am Psychol. 2004; 59(8):676-684.10.1037/0003-066x. 59.8.676 [PubMed: 15554821]

Cohen S, Lemay EP. Why would social networks be linked to affect and health practices? Health Psychol. 2007; 26(4):410-417.10.1037/0278-6133.26.4.410 [PubMed: 17605560]

Davern M, Rodin H, Blewett LA, Call KT. Are the Current Population Survey Uninsurance Estimates Too High? An Examination of the Imputation Process. Health Services Research. 2007; 42(5): 2038-2055. [PubMed: 17850532]

Davies AA, Borland RM, Blake C, West HE. The dynamics of health and return migration. PLoS Med. 2011; 8(6):e1001046.10.1371/journal.pmed.1001046 [PubMed: 21738448]

Duany, Jorge. To send or not to send: Migrant remittances in Puerto Rico, the Dominican Republic, and Mexico. Annals of the American Academy of Political and Social Science. 2010; 630(1):205223.10.1177/0002716210368111

Frank R. International migration and infant health in Mexico. J Immigr Health. 2005; 7(1):1122.10.1007/s10903-005-1386-9 [PubMed: 15744473]

Frank R, Palma-Coca O, Rauda-Esquivel J, Olaiz-Fernandez G, Diaz-Olavarrieta C, Acevedo-Garcia D. The relationship between remittances and health care provision in Mexico. Am J Public Health. 2009; 99(7):1227-1231.10.2105/ajph.2008.144980 [PubMed: 19443828]

Franzini, Luisa; Fernandez-Esquer, Maria Eugenia. The association of subjective social status and health in low-income Mexican-origin individuals in Texas. Social Science \& Medicine. 2006; 63(3):788-804.10.1016/j.socscimed.2006.01.009 [PubMed: 16580107]

Graubard B, Korn E. Predictive Margins with Survey Data. Biometrics. 1999; 55(2):652. [PubMed: 11318229]

Guarnaccia, Peter J.; Pincay, Igda Martínez; Alegría, Margarita; Shrout, Patrick E.; Lewis-Fernández, Roberto; Canino, Glorisa J. Assessing diversity among Latinos: Results from the NLAAS. Hispanic Journal of Behavioral Sciences. 2007; 29(4):510-534. [PubMed: 19672330]

Hamilton ER, Villarreal A, Hummer RA. Individual, Household, and Community U.S. Migration Experience and Infant Mortality in Rural and Urban Mexico. Popul Res Policy Rev. 2009; 28(2): 123-142.10.1007/s11113-008-9097-2 [PubMed: 20047012]

Haro JM, Arbabzadeh-Bouchez S, Brugha TS, de Girolamo G, Guyer ME, Jin R, Kessler RC. Concordance of the Composite International Diagnostic Interview Version 3.0 (CIDI 3.0) with standardized clinical assessments in the WHO World Mental Health surveys. Int J Methods Psychiatr Res. 2006; 15(4):167-180. [PubMed: 17266013]

Hawkley, Louise C.; Cacioppo, John T. Loneliness matters: A theoretical and empirical review of consequences and mechanisms. Annals of Behavioral Medicine. 2010; 40(2):218-227.10.1007/ s12160-010-9210-8 [PubMed: 20652462]

Heeringa, Steven G.; Wagner, James; Torres, Myriam; Duan, Naihua; Adams, Terry; Berglund, Patricia. Sample designs and sampling methods for the Collaborative Psychiatric Epidemiology Studies (CPES). Int J Methods Psychiatr Res. 2004; 13(4):221-240.10.1002/mpr.179 [PubMed: 15719530]

Hondagneu-Sotelo, Pierrette. Introduction: Gender and Contemporary U.S. Immigration. American Behavioral Scientist. 1999; 42(4):565-576.10.1177/00027649921954363

Itzigsohn, José; Giorguli-Saucedo, Silvia. Incorporation, Transnationalism, and Gender: Immigrant Incorporation and Transnational Partitipation as Gendered Processes. International Migration Review. 2005; 39(4):895-920.

Itzigsohn, José; Saucedo, Silvia Giorguli. Immigrant Incorporation and Sociocultural Transnationalism. International Migration Review. 2002; 36(3):766-798.

Jasso, Guillermina; Massey, Douglas S.; Rosenzweig, Mark R.; Smith, James P. Immigrant Health: Selectivity and Acculturation. In: Anderson, NB.; Bulatao, RA.; Cohen, B., editors. Critical Perspectives on Racial and Ethnic Differences in Health in Late Life. Washington, D.C.: The National Academies Press; 2004. p. 227-266. 
Kanaiaupuni SM, Donato KM. Migradollars and mortality: the effects of migration on infant survival in Mexico. Demography. 1999; 36(3):339-353. [PubMed: 10472498]

Kessler, Ronald C.; McLeod, Jane D. Sex differences in vulnerability to undesirable life events. American Sociological Review. 1984; 49(5):620-631.10.2307/2095420

Kessler, Ronald C.; Üstün, T Bedirhan. The World Mental Health (WMH) Survey Initiative Version of the World Health Organization (WHO) Composite International Diagnostic Interview (CIDI). Int J Methods Psychiatr Res. 2004; 13(2):93-121.10.1002/mpr.168 [PubMed: 15297906]

Laria, Amaro J.; Lewis-Fernández, Roberto. Latino Patients. In: Lim, RF., editor. Clinical manual of cultural psychiatry. Arlington, VA US: American Psychiatric Publishing, Inc; 2006. p. 119-173.

Levitt P. Social remittances: migration driven local-level forms of cultural diffusion. Int Migr Rev. 1998; 32(4):926-948. [PubMed: 12294302]

Lindstrom DP, Munoz-Franco E. Migration and maternal health services utilization in rural Guatemala. Soc Sci Med. 2006; 63(3):706-721.10.1016/j.socscimed.2006.02.007 [PubMed: 16580106]

Lu, Yao. Household migration, social support, and psychosocial health: The perspective from migrantsending areas. Social Science \& Medicine. 2012; 74(2):135-142.10.1016/j.socscimed.2011.10.020 [PubMed: 22169626]

McDonough P, Walters V. Gender and health: reassessing patterns and explanations. Soc Sci Med. 2001; 52(4):547-559. [PubMed: 11206652]

Merikangas, Kathleen R.; Ames, Minnie; Cui, Lihong; Stang, Paul E.; Ustun, T Bedirhan; Von Korff, Michael; Kessler, Ronald C. The impact of comorbidity of mental and physical conditions on role disability in the US adult household population. Arch Gen Psychiatry. 2007; 64(10):1180_ 1188.10.1001/archpsyc.64.10.1180 [PubMed: 17909130]

Misra A, Ganda OP. Migration and its impact on adiposity and type 2 diabetes. Nutrition. 2007; 23(9): 696-708.10.1016/j.nut.2007.06.008 [PubMed: 17679049]

Molina KM, Alcántara C. Household structure, family ties, and psychological distress among U.S.born and immigrant Latino women. J Fam Psychol. 2013; 27(1):147-158.10.1037/a0031135 [PubMed: 23421842]

Murphy, Eleanor J.; Mahalingam, Ramaswami. Transnational Ties and Mental Health of Caribbean Immigrants. Journal of Immigrant Health. 2004; 6(4):167-178.10.1023/B:JOIH. 0000045254.71331.5e [PubMed: 16228699]

Murphy, Eleanor J.; Mahalingam, Ramaswami. Perceived congruence between expectations and outcomes: Implications for mental health among caribbean immigrants. American Journal of Orthopsychiatry. 2006; 76(1):120-127.10.1037/0002-9432.76.1.120 [PubMed: 16569136]

Ornelas IJ, Eng E, Perreira KM. Perceived barriers to opportunity and their relation to substance use among Latino immigrant men. J Behav Med. 2011; 34(3):182-191.10.1007/s10865-010-9297-1 [PubMed: 20865312]

Perez, Debra Joy; Fortuna, Lisa; Alegría, Margarita. Prevalence and correlates of everyday discrimination among U.S. Latinos. Journal of Community Psychology. 2008; 36(4):421-433. [PubMed: 19960098]

Portes, Alejandro. Conclusion: Theoretical Convergencies and Empirical Evidence in the Study of Immigrant Transnationalism. International Migration Review. 2003; 37(3):874-892.10.1111/j. 1747-7379.2003.tb00161.x

Portes, Alejandro. Migration, Development, and Segmented Assimilation: A Conceptual Review of the Evidence. Annals of the American Academy of Political and Social Science. 2007; 610:73-97. (ArticleType: research-article / Issue Title: NAFTA and Beyond: Alternative Perspectives in the Study of Global Trade and Development / Full publication date: Mar., 2007/Copyright (C 2007 American Academy of Political and Social Science).

Pressman, Sarah D.; Cohen, Sheldon; Miller, Gregory E.; Barkin, Anita; Rabin, Bruce S.; Treanor, John J. Loneliness, Social Network Size, and Immune Response to Influenza Vaccination in College Freshmen. Health Psychology. 2005; 24(3):297-306.10.1037/0278-6133.24.3.297 [PubMed: 15898866]

Rumbaut, Rubén G. The Making of a People. In: Tienda, M.; Mitchell, F., editors. Hispanics and the Future of America. Washington, D.C.: The National Academies Press; 2006. p. 16-65. 
Sabogal, Fabio; Marín, Gerardo; Otero-Sabogal, Regina; Marín, Barbara V. Hispanic familism and acculturation: What changes and what doesn't? Hispanic Journal of Behavioral Sciences. 1987; 9(4):397-412.10.1177/07399863870094003

Sana, Mariano; Massey, Douglas S. Household Composition, Family Migration, and Community Context: Migrant Remittances in Four Countries. Social Science Quarterly (Blackwell Publishing Limited). 2005; 86(2):509-528.10.1111/j.0038-4941.2005.00315.x

Schiller, Nina Glick; Basch, Linda; Cristina Szanton, Blanc. From Immigrant to Transmigrant: Theorizing Transnational Migration. Anthropological Quarterly. 1995; 68(1):48-63.

Schwartz C, Meisenhelder JB, Ma Y, Reed G. Altruistic social interest behaviors are associated with better mental health. Psychosom Med. 2003; 65(5):778-785. [PubMed: 14508020]

Stata Corporation. Stata statistical software release 10.1. College Station, Texas: Stata Corporation; 2008.

Tabachnick, BG.; Fidell, LS. Using Multivariate Statistics. 5. Boston, MA: Allyn and Bacon; 2007.

Tamaki E. Transnational Home Engagement among Latino and Asian Americans: Resources and Motivation. Int Migr Rev. 2011; 45(1):148-173.10.1111/j.1747-7379.2010.00842.x [PubMed: 21647239]

Ullmann, S Heidi; Goldman, Noreen; Massey, Douglas S. Healthier before they migrate, less healthy when they return? The health of returned migrants in Mexico. Social Science \& Medicine. 2011; 73(3):421-428.10.1016/j.socscimed.2011.05.037 [PubMed: 21729820]

Umberson, Debra; Chen, Meichu D.; House, James S.; Hopkins, Kristine. The effect of social relationships on psychological well-being: Are men and women really so different? American Sociological Review. 1996; 61(5):837-857.10.2307/2096456

Umberson, Debra; Crosnoe, Robert; Reczek, Corinne. Social relationships and health behavior across the life course. Annual Review of Sociology. 2010; 36:139-159.10.1146/annurevsoc-070308-120011

United States Census Bureau. The Hispanic Population: 2010. 2010 Census Briefs. 2011:1-16.

United States Census Bureau. The Foreign-Born Population in the United States: 2010. 2012

United States Department of Commerce. Profile of U.S. Resident Travelers Visiting Overseas Destinations: 2010 Outbound. Washington, DC: 2010.

Viruell-Fuentes EA, Schulz AJ. Toward a dynamic conceptualization of social ties and context: implications for understanding immigrant and Latino health. Am J Public Health. 2009; 99(12): 2167-2175.10.2105/ajph.2008.158956 [PubMed: 19833986]

World Bank. Migration and Remittances Fact Book, 2011. 2011. from http://go.worldbank.org/ QGUCPJTOR0 


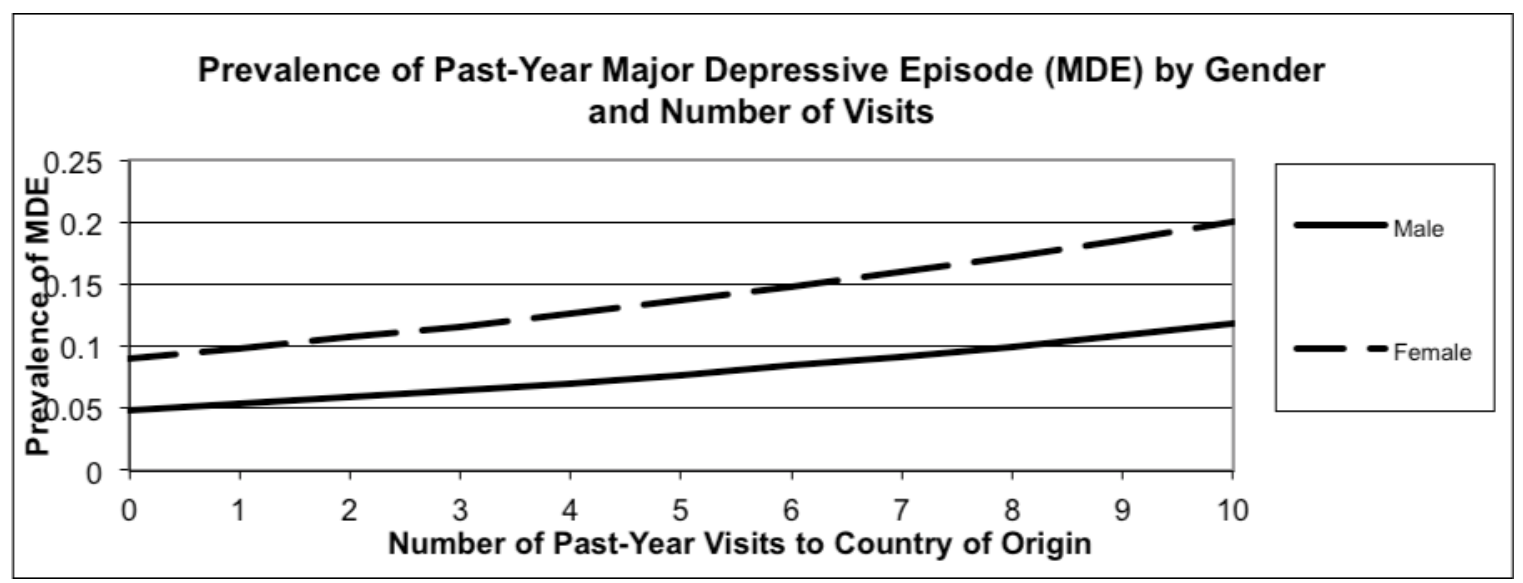

Figure 1.

Predicted probability of past-year major depressive episode (MDE) as a function of gender and number of visits to the country of origin among Latino immigrants. 


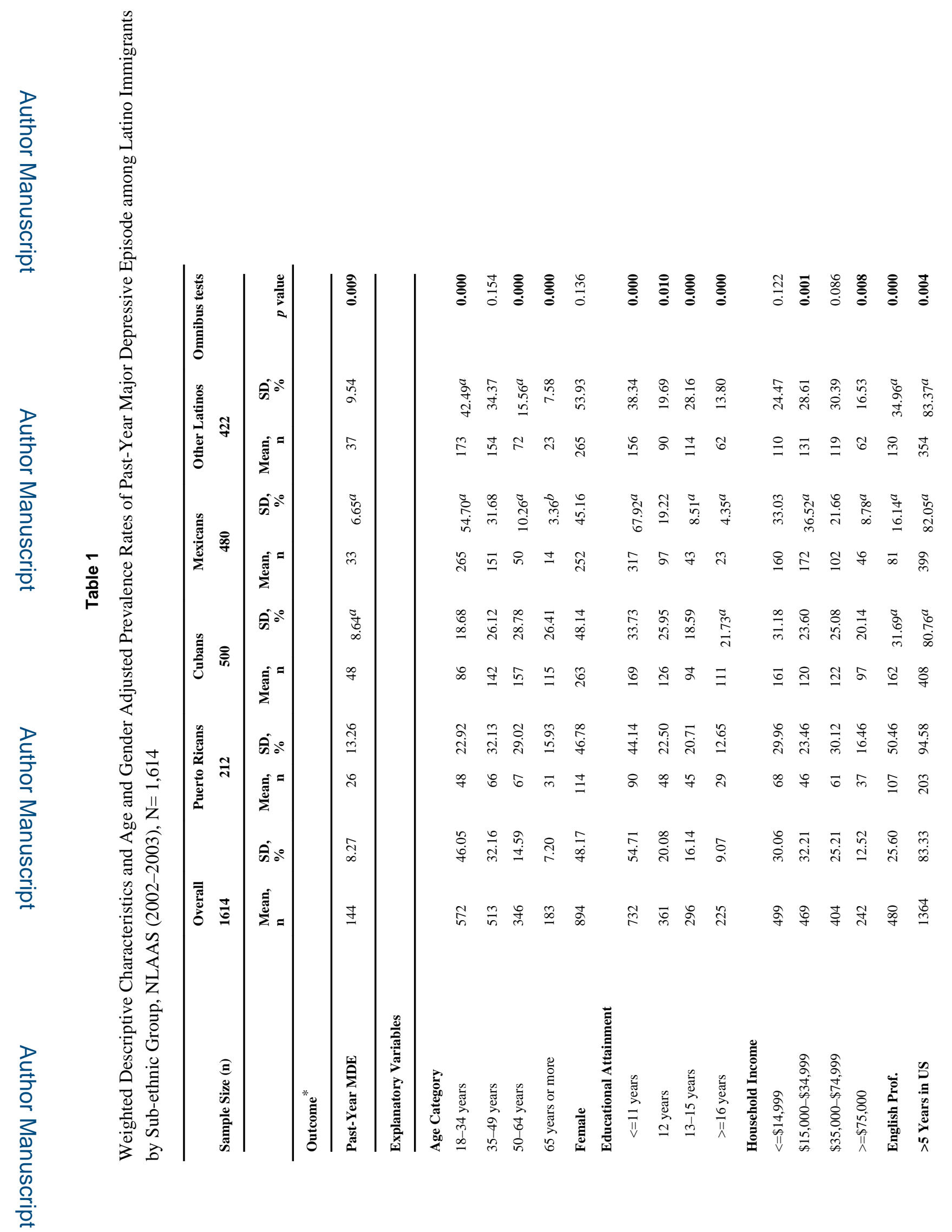

Cultur Divers Ethnic Minor Psychol. Author manuscript; available in PMC 2016 July 01. 

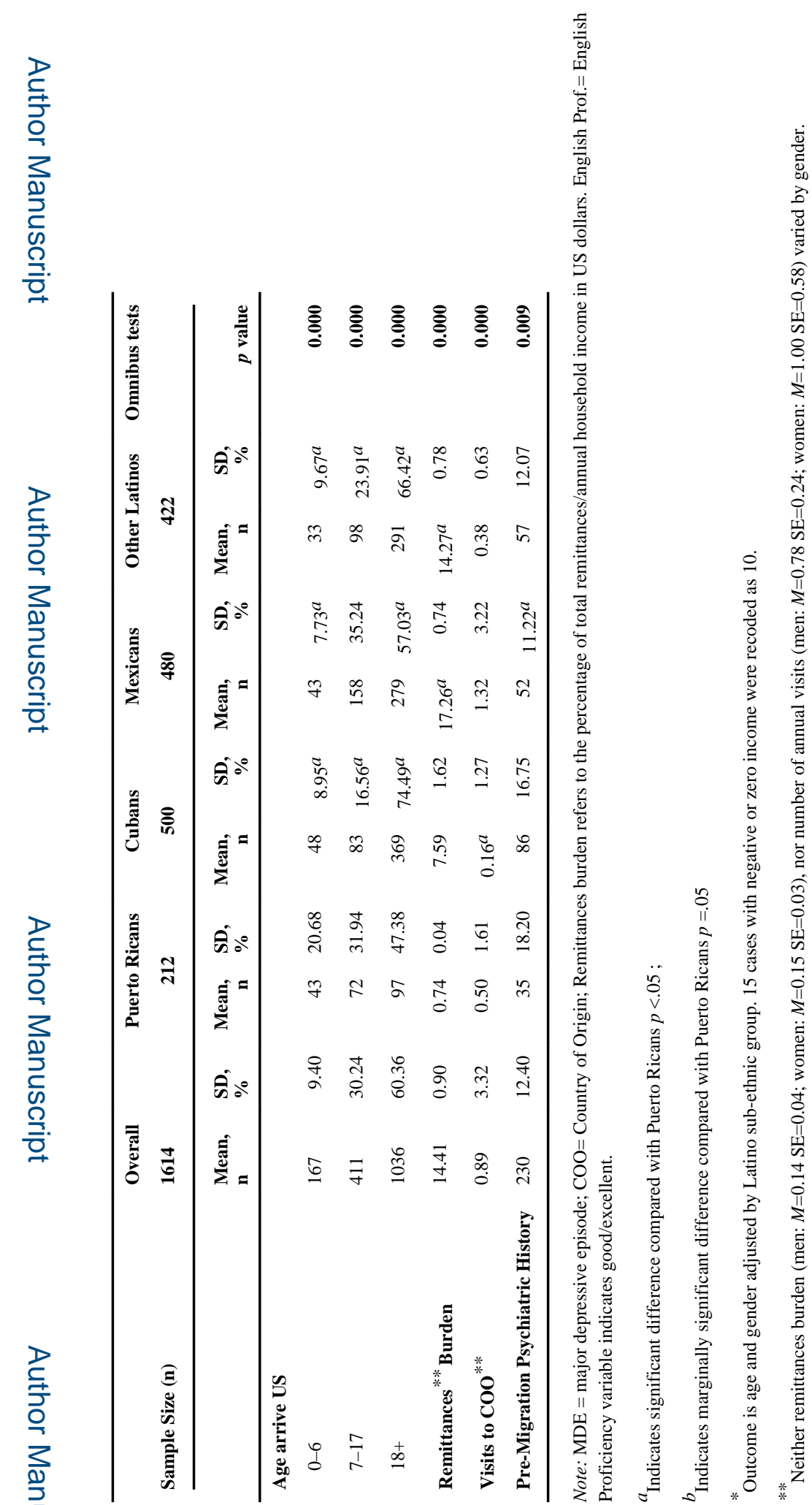

Cultur Divers Ethnic Minor Psychol. Author manuscript; available in PMC 2016 July 01. 


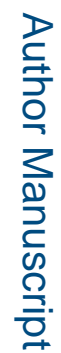

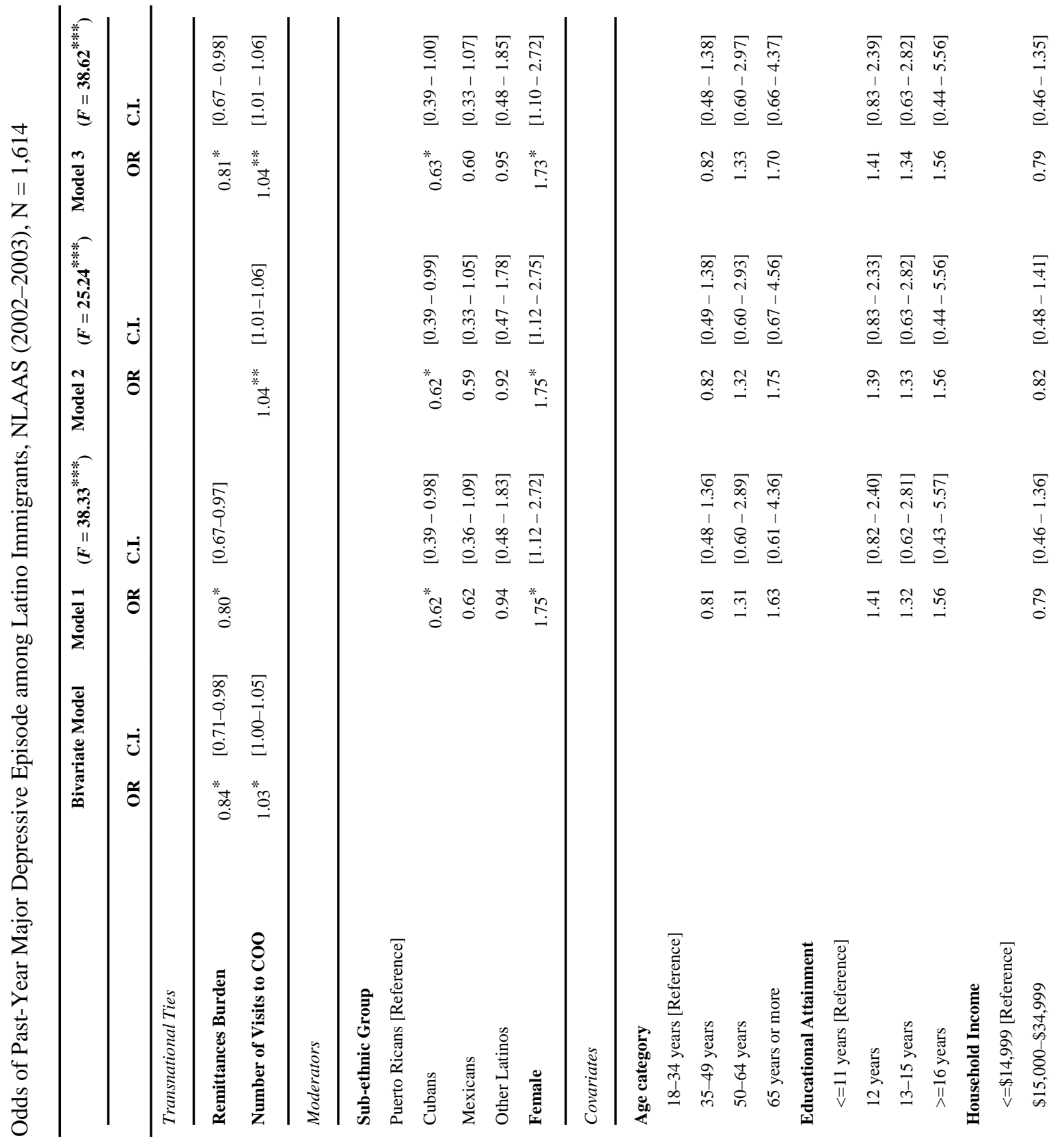

Cultur Divers Ethnic Minor Psychol. Author manuscript; available in PMC 2016 July 01. 


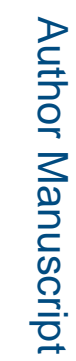

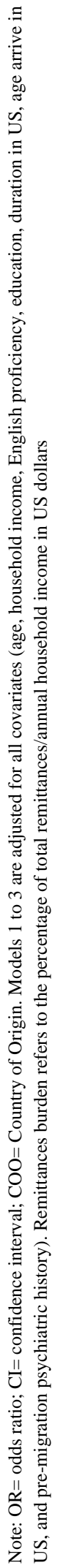

Cultur Divers Ethnic Minor Psychol. Author manuscript; available in PMC 2016 July 01. 
Table 3

Final Model on Association of Number of Visits with Depression including Significant Gender X Number of Visits Interaction Term, NLAAS (2002-2003), N=1614

\begin{tabular}{|l|l|l|}
\hline & Model $\mathbf{4}$ & F=36.69**** \\
\hline & O.R. & C.I. \\
\hline Number of Visits to Country of Origin & $1.14 * * *$ & $(1.10-1.18)$ \\
\hline Female & $2.20^{* *}$ & $(1.36-3.55)$ \\
\hline Female*Number of Visits to Country of Origin & $0.83 * * *$ & $(0.77-0.89)$ \\
\hline
\end{tabular}

Note. OR= Odds Ratio; $\mathrm{CI}=$ Confidence Interval. Model 4 is adjusted for all covariates (age, household income, English proficiency, education, duration in US, age arrive in US, and pre-migration psychiatric history), and remittances burden. 